\title{
Three-dimensional miniaturized power inductors realized in a batch-type hybrid technology
}

\author{
Menouer Saidani and Martin A M Gijs \\ Institute of Microelectronics and Microsystems, Swiss Federal Institute of Technology \\ Lausanne, CH-1015 Lausanne EPFL, Switzerland \\ E-mail: menouer.saidani@epfl.ch
}

Received 8 January 2002, in final form 11 March 2002

Published 19 June 2002

Online at stacks.iop.org/JMM/12/470

\begin{abstract}
We present a new hybrid technology for the realization of three-dimensional millimetre-size inductors for low-power (0.1-1 W) applications. Our devices consist of electroplated planar $\mathrm{Cu}$ coils, realized within a high-resolution $(5 \mu \mathrm{m})$ polyimide flex-foil process, and $\mathrm{mm}$-size ferrite magnetic cores, obtained by three-dimensional micropatterning of ferrite wafers using powder blasting microerosion. Our devices range in volume between 10 and $1.5 \mathrm{~mm}^{3}$ and we characterize their inductive and resistive properties as a function of frequency.

(Some figures in this article are in colour only in the electronic version)
\end{abstract}

\section{Introduction}

Today there is an increasing demand for miniaturized and planar magnetic devices, such as inductors and transformers, for power electronics applications. Miniaturized switching converters operating at high frequency, high energy density and high efficiency are required for use in communications, military/aerospace applications and computer/peripheral or other portable devices.

It is also required that these inductive devices have high values of inductance, saturation current and quality factor $(Q)$. Miniaturization also implies that operating frequencies increase, as at high frequencies $(0.1-1 \mathrm{MHz})$ more power cycles can pass the inductive device within a given time. A lot of work has been done to replace discrete miniaturized magnetic components by fully integrated magnetic devices. However, the magnetic properties of such integrated structures may be very different from those of the bulk magnetic materials. For example, Park et al [1] and Ahn et al [2] reported on $4 \mathrm{~mm} \times 1 \mathrm{~mm} \times 0.13 \mathrm{~mm}$ size inductors based on $15 \mu \mathrm{m}$ thick electroplated $\mathrm{Ni}_{80} \mathrm{Fe}_{20}$ and $\mathrm{Ni}_{50} \mathrm{Fe}_{50}$ magnetic cores. The structure is realized by a number of sputter deposition, electroplating, photoresist spinning and patterning steps. Inductance values of approximately $0.1-0.4 \mu \mathrm{H}$ were reported at $1 \mathrm{kHz}-1 \mathrm{MHz}$. Löchel et al [3] have used thick resist technology, sputtering and electroplating/etching methods to fabricate coils of a few mm size, based on $\mathrm{NiFe}$ core material. Inductance values of the order of $1 \mu \mathrm{H}$ were reported at $125 \mathrm{kHz}$. Microtransformers of size $5 \mathrm{~mm}$ integrated with diodes on a $\mathrm{Si}$ wafer were also reported by Mino et al [4, 5]. These transformers are based on an amorphous magnetic core prepared by sputtering in the form of three separate layers of CoZrRe, each $5 \mu \mathrm{m}$ thick, with $0.1 \mu \mathrm{m}$ $\mathrm{SiO}_{2}$ spacer layers. This layered configuration was chosen exactly to reduce eddy current losses in the magnetic core. The reported inductance values were in the range of $0.5-1 \mu \mathrm{H}$. A specially configured transformer was realized by Yamasawa et al [6] by sandwiching primary and secondary coils in between two $10 \mu \mathrm{m}$ thick amorphous CoZr layers. An inductance value of $8.5 \mu \mathrm{H}$ at $1 \mathrm{MHz}$ was obtained by this rather large planar device of dimensions $40 \mathrm{~mm} \times 30 \mathrm{~mm}$. A spiral coil type thin film microtransformer $\left(2.4 \times 3.1 \mathrm{~mm}^{2}\right)$, using RF-sputtered CoNbZr layers, was also proposed by Yamaguchi et al for $\mathrm{MHz}$ switching regulators [7]. These micromachined inductive devices are mostly based on metallic magnetic materials and are not primarily intended to function in a power application.

On the other hand, ferrite is one of the widely used magnetic core materials for high frequency power inductors and transformers. Since it has higher resistivity than metallic magnetic materials, eddy currents losses are strongly reduced [8]. During recent years, a large research effort has been 
developed in the field of the so-called planar magnetics, where one integrates three-dimensional (3D) ferrite cores of reduced height with $\mathrm{Cu}$ windings realized in printed circuit board (PCB) technology [9-11]. In the microsystems field, ferritebased inductors have been fabricated using screen printed polymer/ferrite layer composites, and inductances of the $0.5-1.5 \mu \mathrm{H}$ range have been achieved $[12,13]$. Here, fine ferrite particles are introduced into a polyimide matrix to form a composite magnetic core, but the magnetic permeabilities, and hence the inductance values, are much lower than those obtained when using conventional bulk ferrite materials. We have recently proposed a batch-type solution for the fabrication of 3D inductors, where we combined E-shaped magnetic ferrite cores, micromachined from ferrite wafers, with planar $\mathrm{Cu}$ coils, realized using commercially available flex-foil technology [14]. The commercial technology is based on the gluing of thin $\mathrm{Cu}$ foils on a polyimide substrate and their subsequent micropatterning in a wet etching process. Due to $\mathrm{Cu}$ foil/polyimide detachment problems and mask underetching effects, actually a minimum winding width $w=$ 25-30 $\mu \mathrm{m}$ and a winding pitch $p=50-60 \mu \mathrm{m}$ are feasible (see, for example, [15]). Clearly, this minimum dimension presents a strong limit to the extreme miniaturization of inductive power devices, as the inductance value scales with the square of the number of windings that can be fitted into a given inductor volume.

In this work, we propose an improved technology for the batch-fabrication of 3D inductors, with which we open the way to economically feasible ultra-miniaturized low-power $(\leqslant 1 \mathrm{~W})$ applications. Our devices consist of two E-shaped magnetic ferrite cores, sandwiching a polyimide-based coil carrying the electrical windings. As mentioned before, the 3D ferrite cores are microstructured out of mm-thick ferrite wafers using a batch-type micropowder blasting process [16]. In this way, we can realize many cores in parallel and assemble them at wafer-level with the electrical winding patterns. The electrical windings are realized using an in-house developed flex-foil process with high-resolution potential, consisting of several polyimide spinning, $\mathrm{Cu}$ electroplating and planarization steps. We have measured the electrical properties of our devices as a function of frequency and find inductance values up to $100 \mu \mathrm{H}$ for inductor volumes of the order of $10 \mathrm{~mm}^{3}$.

\section{Fabrication process}

\subsection{Magnetic cores}

For the magnetic cores, we use high relative permeability $\left(\mu_{\mathrm{r}}=1800\right) 3 \mathrm{~F} 3$ ferrite wafers of Philips [17]. The 3D ferrite E-cores are micromachined in $1 \mathrm{~mm}, 0.75 \mathrm{~mm}$ and $0.5 \mathrm{~mm}$ thick ferrite wafers using a mechanical microerosion by powder blasting [16]. A $0.5 \mathrm{~mm}$ thick stainless steel mask, which is in mechanical contact with the wafer, is used to protect non-eroded areas. The $x$ - and $y$-axis translation of the nozzle provides a uniform exposure of the fixed ferrite wafer. An example of an array of ferrite cores, after fabrication and glueing on blue tape, is shown in figure $1(a)$. Figure $1(b)$ is a photomicrograph of a single E-core.

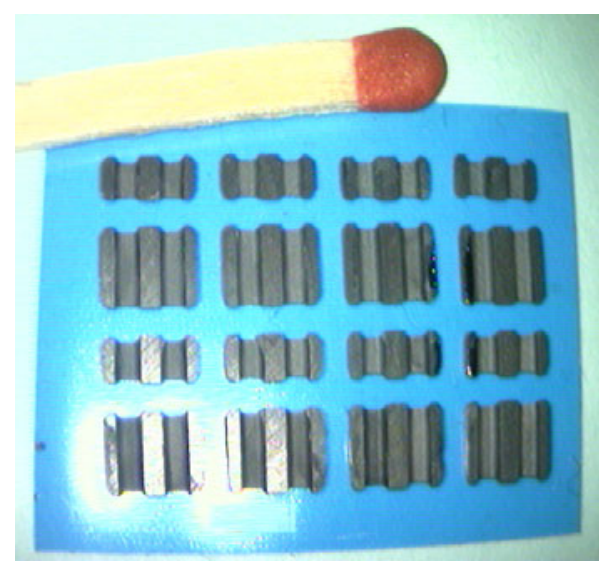

(a)

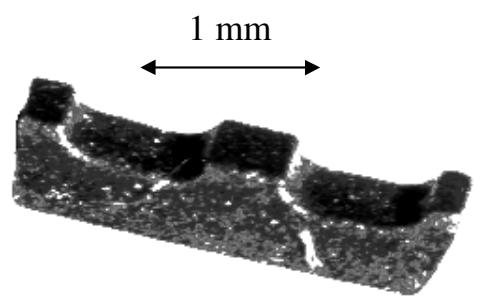

(b)

Figure 1. (a) Array of structured ferrite E-cores, powder blasted in a ferrite wafer and $(b)$ a photomicrograph of a single microstructured ferrite E-core.

\subsection{Coils}

Presently, standard available flex-foil technology is resolutionlimited to structures with a $\mathrm{Cu}$ width $w=25-30 \mu \mathrm{m}$ and a winding pitch $p=50-60 \mu \mathrm{m}$. To enable higher winding densities, we have elaborated a new flex-foil process, which takes advantage of standard clean room wafer-based microfabrication techniques. This process, the sequence of which is shown in figure 2, starts with a $\mathrm{Si}$ substrate (for mechanical support), which is laminated with a $12.5 \mu \mathrm{m}$ thick polyimide (Kapton) foil, using $12.5 \mu \mathrm{m}$ acrylic adhesive tape. To planarize the surface, a thin layer ( $7 \mu \mathrm{m}$ after cure) of liquid polyimide (PI2611 from Dupont) is spun on the top of the Kapton layer after application of an adhesion promoter (VM651 from Dupont).

After coating, the polyimide is cured in nitrogen medium in a programmable oven $\left(1 \mathrm{~h}\right.$ at $150{ }^{\circ} \mathrm{C}$, followed by $1 \mathrm{~h}$ at $200{ }^{\circ} \mathrm{C}$ ). Normally, PI2611 polyimide series must be cured at $350{ }^{\circ} \mathrm{C}$ to eliminate all solvents. To protect the Kapton layer from excessive heating, the curing is limited to $200{ }^{\circ} \mathrm{C}$ in our process.

Subsequently, a $20 \mathrm{~nm} \mathrm{Cr}$ adhesion layer is deposited on the polyimide, followed by $200 \mathrm{~nm}$ of $\mathrm{Cu}$ to form a seed layer for electroplating. A $8 \mu \mathrm{m}$ thick layer of Shipley SJR5740 photoresist is then spun on, exposed with mask 1 and developed to obtain thick moulds for the lower part of the windings. $\mathrm{Cu}$ is then electroplated into the photoresist moulds using $\mathrm{a} \mathrm{CuSO}_{4}$ bath (figure 2(a)). Subsequently, the $\mathrm{Cu}$ seed layer is removed using a $\mathrm{H}_{4} \mathrm{FeNO}_{8} \mathrm{~S}_{2}$ solution, followed by removal of the $\mathrm{Cr}$ adhesion layer in a solution of $\mathrm{KMnO}_{4}$ and $\mathrm{Na}_{3} \mathrm{PO}_{4}$. 
(a)

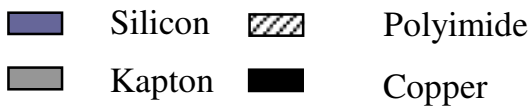

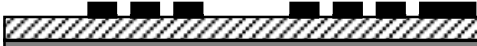

(b)

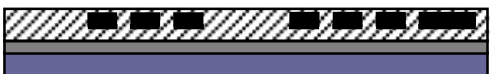

(c)

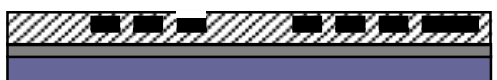

(d)

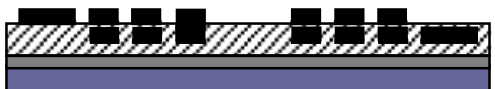

(e)

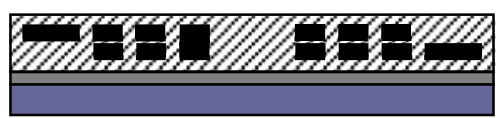

$(f)$

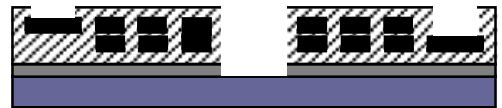

(g)

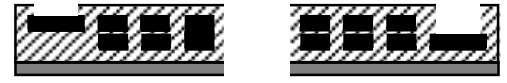

Figure 2. Fabrication sequence for high-resolution polyimide-based double-layered coils on flexible Kapton support: $(a)$ electroplating of the first layer of the coil, $(b)$ polyimide isolation layer deposition, $(c)$ via hole etching, $(d)$ electroplating of the second layer of the coil, $(e)$ polyimide isolation layer deposition, $(f)$ feed-through hole and contact path holes etching, $(g)$ final separation of the flexible structures from the $\mathrm{Si}$ substrate.

One layer of polyimide is then spun and cured to isolate the $\mathrm{Cu}$ windings. After this step the topography of the surface was not flat and did not allow high-resolution patterning of the next level.

Therefore a chemical mechanical polishing procedure is used for planarization, using a $0.05 \mu \mathrm{m}$ silica slurry. (figure 2(b)). Next, via holes are plasma etched in $\mathrm{O}_{2}$, using a $800 \mathrm{~nm}$ thick PECVD $\mathrm{SiO}_{2}$ mask. Hereafter, the $\mathrm{SiO}_{2}$ mask is removed using wet etching (figure 2(c)).

From this point, fabrication continues with the next level of windings by depositing a new seed layer on the planarized surface and by repeating the sequence of steps described before (figure $2(d)$ ). After removal of the seed layer, a polyimide passivation layer is applied and cured to protect the top of the windings from oxidation (figure $2(e)$ ). Finally, a $\mathrm{SiO}_{2}$ mask is deposited and the polyimide is etched in an $\mathrm{O}_{2}$ plasma to create the through-holes for the positioning of the E-cores and to clear the contact paths (figure $2(f)$ ). To separate the flexible structure from the Si substrate, a bath of acetone is used to remove the adhesive between the Kapton film and the wafer (figure $2(g)$ ).

Figure $3(a)$ is a photograph of three different sizes of coils together with their respective ferrite E-cores. Figure $3(b)$ is an assembled inductor.

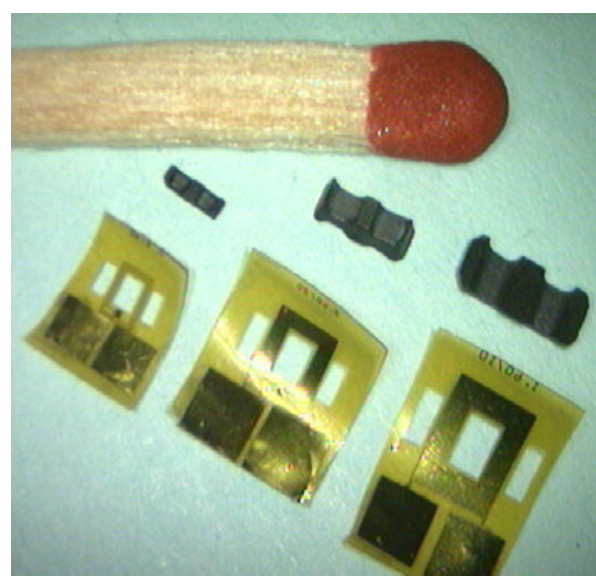

(a)

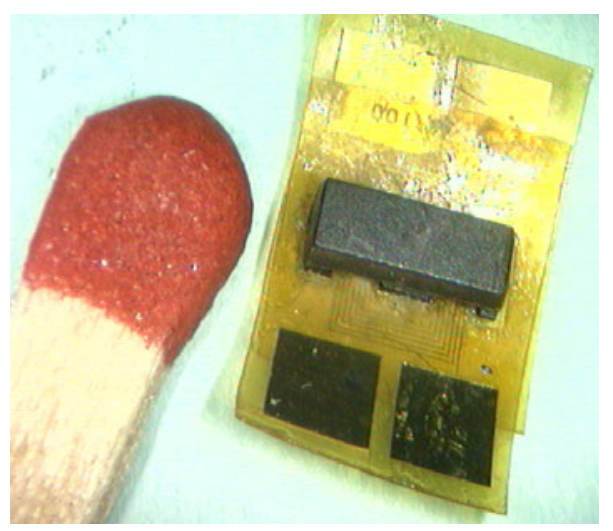

(b)

Figure 3. (a) Photograph of various size flex foil coils with their respective ferrite cores and $(b)$ assembled inductor.

Table 1. A set of three realized and electrically characterized polyimide-based coils.

\begin{tabular}{llllll}
\hline $\begin{array}{l}\text { Sample } \\
\text { number }\end{array}$ & $w(\mu \mathrm{m})$ & $p(\mu \mathrm{m})$ & $N$ & $\begin{array}{l}L(\mu \mathrm{H}) \\
@ 10 \mathrm{kHz}\end{array}$ & $C_{\text {cal }}(\mathrm{pF})$ \\
\hline 1 & 60 & 100 & 14 & 2 & 100 \\
2 & 50 & 60 & 24 & 17 & 140 \\
3 & 40 & 50 & 30 & 90 & 145 \\
\hline
\end{tabular}

\section{Experimental results and discussion}

Electrical properties of the fabricated samples are measured using a Hewlett Packard 4194A impedance/gain-phase analyser. Using a logarithmic frequency sweep between $10^{3}$ and $10^{7} \mathrm{~Hz}$ with a sinusoidal signal level of $500 \mathrm{mV} \mathrm{rms}$, inductance and resistance are recorded. We present results on the samples described in table 1 . Here, we present the winding width $w$, winding pitch $p$, the measured inductance $L$ at $10 \mathrm{kHz}$ and the calculated inter-winding capacitance $C_{\text {cal }}$ of the coil for three different samples.

The results reported in table 1 are characterized by a minimum winding width of $40 \mu \mathrm{m}$ and a minimum winding interspacing of $10 \mu \mathrm{m}$. Although we were able to produce windings widths down to $10 \mu \mathrm{m}$, solder contacts to these narrow lines proved to be difficult to realize (breaking of the line at the edge of the contact path) and we were not able to characterize these samples electrically. Therefore, we will 

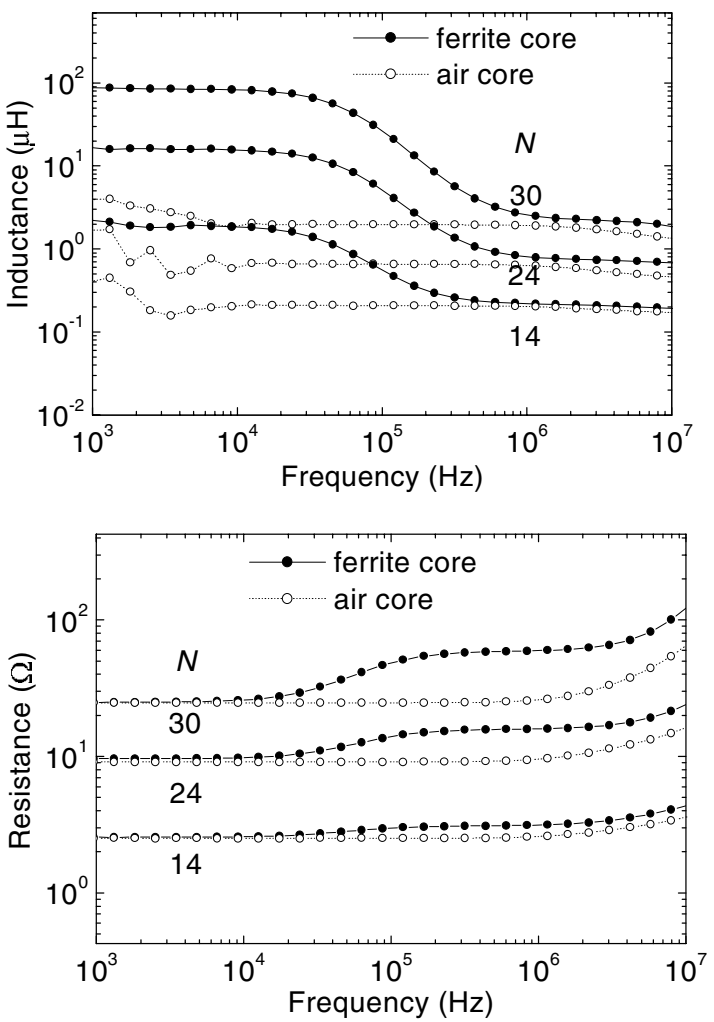

Figure 4. Dependence of the inductance and the resistance versus frequency for the samples of table 1 with air core and ferrite core.

redesign our contacts in the future microfabrication process. With a higher winding density, we should be able to realize still larger inductances in future.

Figure 4 shows inductance (a) and resistance (b) measurements, respectively, of each device of table 1 as a function of frequency, with and without the application of the ferrite cores and with the number of windings $N$ as a parameter. One clearly sees the strong enhancement (factor 50-100) of the inductance due to the presence of the ferrite for frequencies up to $0.1 \mathrm{MHz}$. Resistance rises in the 0.1-1 MHz range are due to the increasing magnetic core and electrical winding losses at high frequencies. The drop of the inductance in the $0.1-1 \mathrm{MHz}$ range for the ferrite-based core is more pronounced than expected for the frequency dependence of the intrinsic permeability of the magnetic core [17]. Figure 5 shows the frequency-dependent permeability from the $3 \mathrm{~F} 3$ ferrite material (right axis), with the measured inductance with and without ferrite core for sample 3 of table 1 (left axis). It is clear that the decrease in the inductance for the ferrite-core sample starts at lower frequencies than the decrease in the permeability.

We think that this phenomenon is due to capacitive interwinding coupling of our coils, which shorts out the number of windings and ferrite core at increasing frequencies. Indeed, our coils consist of two stacked spiral inductors, vertically separated by only $1 \mu \mathrm{m}$ of polyimide. Therefore, at high frequencies the capacitance between the two inductors shunts the magnetic circuit and leads to a strong fall-off in the inductance. In future, coil design needs to be adapted to minimize capacitive coupling, if one wants to enable inductive device operation at frequencies above $0.1 \mathrm{MHz}$. For example,

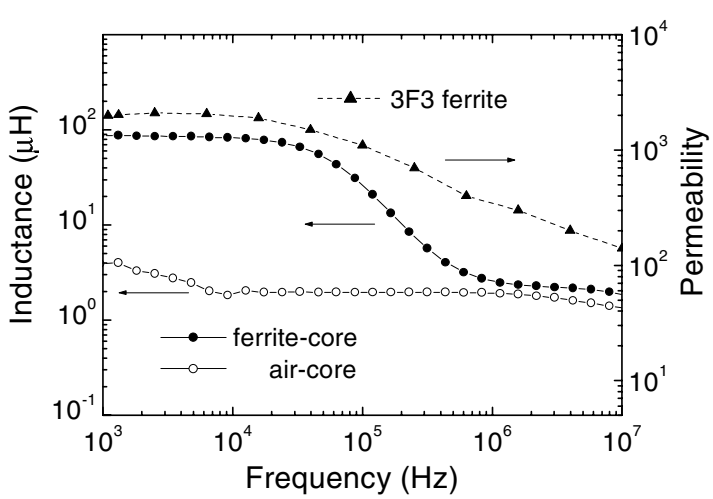

Figure 5. 3F3 ferrite permeability as a function of frequency compared to a typical behaviour of the inductance of the coil, with and without core.

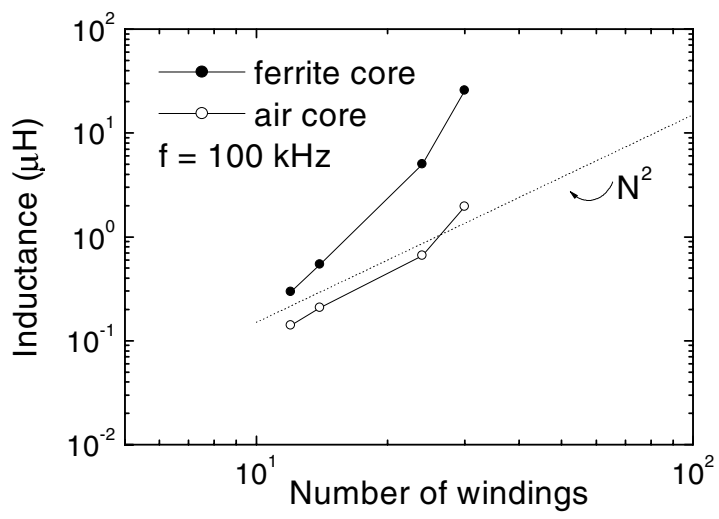

Figure 6. Power-law dependence of the inductance on the number of windings $N$ at $100 \mathrm{kHz}$, without and with ferrite core.

we can increase the interlayer dielectric by spinning thicker polyimide layers (a measure that would require electroplating of a thicker $\mathrm{Cu}$ layer within the vias) or we can position the windings of the different layers in a way to minimize interlayer overlap. One should note that in the present design, the windings of lower and upper layer of the coils were superimposed, thereby maximizing capacitive coupling.

Figure 6 is a double logarithmic plot of the inductance as a function of the number of windings $N$ at $f=100 \mathrm{kHz}$. Without the ferrite core, we find the typical $N^{2}$ power-law behaviour. For an inductor with assembled ferrite core, we observe a deviation of the $N^{2}$ behaviour which can be attributed to variations in parasitic air gaps, core clamping, and are most probably due to capacitive inter-winding effects.

\section{Conclusions}

We have developed a high-resolution flex-foil process for the realization of miniaturized $\mathrm{Cu}$ coils and combined it with an original way of fabricating miniaturized E-cores from ferrite wafers to realize inductors in the $\mathrm{mm}^{3}$ volume range. We have measured inductance values in the $100 \mu \mathrm{H}$ range at frequencies below $0.1 \mathrm{MHz}$. We think that our technique opens interesting perspectives for extremely miniaturized power applications. 


\section{Acknowledgments}

We would like to express our thanks to Dr Etienne Bornand and M Farid Amalou for valuable discussions and for their contributions to this project.

\section{References}

[1] Park J Y and Allen M G 1996 A comparison of micromachined inductors with different magnetic core materials Proc. IEEE 46th Electronic Components and Technology Conference (Orlando, FL) pp 375-81

[2] Ahn C, Kim Y and Allen M G 1996 A comparison of two micromachined inductors (bar and meander type) for fully integrated boost dc/dc power converters IEEE Trans. Power Electron. 11 239-45

[3] Löchel B, Maciossek A, Rothe M and Windbracke W 1996 Microcoils fabricated by UV depth lithography and galvanoplating Sensors Actuators A 54 663-8

[4] Mino M, Yachi T, Tago A, Yanagisawa K and Sakakibara K 1996 Planar microtransformer with monolithically integrated rectifier diodes for micro-switching converters IEEE Trans. Magn. 32 291-6

[5] Yachi T, Mino M, Tago A, Yanagisawa K and Sakakibara K 1992 A new planar microtransformer for use in microswitching converters IEEE Trans. Magn. 28 1969-73

[6] Yamasawa K, Maruyama K, Hirohama I and Biringer P P 1990 High frequency operation of a planar-type microtransformer and its application to multilayered switching regulators IEEE Trans. Magn. 26 1204-9
[7] Yamaguchi K, Suguwara E, Nakajima O and Matsuki H 1993 Load characteristics of a spiral coil type thin film microtransformer IEEE Trans. Magn. $293207-9$

[8] Goldberg A, Kassakian J and Schlecht M 1989 Issues related to $1-10 \mathrm{MHz}$ trasformer design IEEE Trans. Power Electron. 4 113-23

[9] van der Linde D, Boon C A M and Klaassens J B 1991 Design of a high-frequency planar power transformer in multilayer technology IEEE Trans. Indust. Electron. 38 137-41

[10] Ben-Yaakov S The Benefits of Planar Magnetics in HF Power Conversion (Rishon-Le Zion, Israel: Payton, Inc.)

[11] Dai N, Lofti A W, Skutt G, Tabisz W and Lee F C A 1994 comparative study of high-frequency, low-profile planar transformer technologies Proc. IEEE 9th Applied Power Electronics Conference and Exposition pp 226-32

[12] Park J Y and Allen M G 1997 Low temperature fabrication and characterization of integrated packaging-compatible, ferrite-core magnetic devices Proc. IEEE 12th Applied Power Electronics Conference and Exposition vol 1 pp 361-7

[13] Park J Y, Lagorce L K and Allen M G 1997 Ferrite-based integrated planar inductors and transformers fabricated at low-temperature IEEE Trans. Magn. 33 3322-4

[14] Amalou F, Bornand E L and Gijs M A M 2001 Batch-type millimetre-size transformers for miniaturised power applications IEEE Trans. Magn. 37 2999-3003

[15] Dyconex product information webpage www.dyconex.com

[16] Belloy E, Thurre S, Walckiers E, Sayah A and Gijs M A M 2000 The introduction of powder blasting for sensor and microsystem applications Sensors Actuators A 84 330-7

[17] Philips catalogue 1999 Magnetic Products, Soft Ferrites 